\title{
Glial Fibrillary Acidic Protein (GFAP) in Oligodendrogliomas: A Reflection of Transient GFAP Expression by Immature Oligodendroglia
}

\author{
V. Jagadha, W.C. Halliday, L.E. Becker
}

\begin{abstract}
Fourteen pure oligodendrogliomas were studied by light- and electronmicroscopy and immunohistochemistry to examine glial fibrillary acidic protein (GFAP) positivity in the tumors. To compare the immunohistochemical staining patterns of neoplastic oligodendroglia and immature oligodendroglia, myelination glia in the white matter of eight normal brains from children under 6 months of age were studied. The tumors possessed light microscopic and ultrastructural features characteristic of oligodendrogliomas. Microtubules were found in the cytoplasm of nine tumors on electronmicroscopy. In one, intermediate filaments and microtubules were observed in occasional tumor cells with polygonal crystalline structures in the cytoplasm. Using the peroxidase-antiperoxidase technique, all specimens were stained for GFAP, vimentin, S-100 and neuron-specific enolase (NSE). In nine tumors, variable numbers of cells with an oligodendroglial morphology reacted positively for GFAP. All tumors were positive for S-100 and negative for vimentin and NSE. The myelination glia in the eight normal brains stained positively for GFAP but not for vimentin. Vimentin is expressed by developing, reactive and neoplastic astrocytes. Thus, GFAP positivity combined with vimentin negativity in both neoplastic and immature oligodendroglia suggests that GFAP positivity in oligodendrogliomas may reflect the transient expression of this intermediate filament by immature oligodendroglia.
\end{abstract}

RÉSUMÉ: Les proténes fibrillaires acides de la glie (PFAG) dans les oligodendrogliomes: une réflexion de l'expression transitoire de PFAG par l'oligodendroglie immature Quatorze oligodendrogliomes pures ont étéétudiés par microscopie optique et électronique et immunohistochimie pour examiner la positivité aux protéines fibrillaires acides de la glie (PFAG) dans les tumeurs. Afin de comparer les patterns de coloration immunohistochimique de l'oligodendroglie néoplastique et de l'oligodendroglie immature, la glie de myélinisation dans la substance blanche de huit cerveaux normaux provenant d'enfants de moins de 6 mois a été étudiée. A la microscopie optique et électronique, les tumeurs possédaient des particularités caractéristiques des oligodendrogliomes. On a trouvé des microtubules dans le cytoplasme de 9 tumeurs à la microscopie électronique. On a observé dans une tumeur des filaments intermédiaires et des microtubules dans quelques cellules tumorales ainsi que des structures cristallines polygonales dans le cytoplasme. En utilisant la technique peroxydase-antiperoxydase, tous les échantillons ont été colorés pour les PFAG, la vimentine, le S-100 et l'énolase spécifique aux neurones (ESN). Dans les neuf tumeurs, un nombre variable de cellules possédant une morphologie de type oligodendroglial avait une réaction positive pour les PFAG. Toutes les tumeurs étaient positives pour le S-100 et négatives pour la vimentine et l'ESN. La glie de myélinisation dans les huit cerveaux normaux présentaient une coloration positive pour les PFAG, mais négative pour la vimentine. La vimentine est exprimée par les astrocytes en développement, réactionnels et néoplasiques. Ainsi, la positivité pour les PFAG associée à la négativité pour la vimentine dans l'oligodendroglie tant néoplasique qu'immature, suggère que la positivité pour les PFAG dans les oligodendrogliomes peut refléter l'expression transitoire de ce filament intermédiaire par l'oligodendroglie immature.

Can. J. Neurol. Sci. 1986; 13:307-311

From the Division of Neuropathology, University of Toronto, The Hospital for Sick Children and the Toronto General Hospital, Toronto Presented in part at the Annual Meeting of the American Association of Neuropathologists. June 13-16, 1985, Boston, Massachusetts Received April 7, 1986. Accepted July 29.1986

Reprint requests to: Dr. L.E. Becker. Division of Neuropathology. The Hospital for Sick Children, 555 University Avenue. Toronto. Ontario. Canada MSG IX8 
Since the initial isolation of the glial fibrillary acidic protein (GFAP) by Eng and co-workers ${ }^{1}$ and Bignami et $\mathrm{al}^{2}$ from multiple sclerosis plaques, and its subsequent recognition as an astrocytic marker, ${ }^{3}$ its distribution in various neoplasms of the central nervous system has been widely studied. 4.5 The interpretation of GFAP positivity in oligodendrogliomas has been a subject of much speculation. ${ }^{6-10}$ While the presence of an astrocytic component in a mixed astrocytic-oligodendroglial tumor is well known, there is now an increasing recognition of the presence of GFAP in tumor cells with features otherwise typical of oligodendroglia. ${ }^{6 \cdot 10}$ Such cells have been variably interpreted as representing reactive astrocytes, oligodendroglia with astrocytic differentiation, transitional astrocytic-oligodendroglial forms or immature oligodendroglia. We studied 14 oligodendrogliomas by light- and electronmicroscopy and immunohistochemically to examine the presence of GFAP positivity in neoplastic oligodendroglia.

\section{Materials AND Methods}

The oligodendrogliomas from the neuropathology files between 1964 and 1984 at Toronto General Hospital and The Hospital for Sick Children, Toronto, were examined. Mixed astrocyticoligodendroglial tumors were excluded and only the 14 tumors with tissue for adequate immunohistochemical evaluation were selected.

For light-microscopy, formalin-fixed, paraffin-embedded tissue was cut in $5 \mu \mathrm{m}$ thick sections that were stained with the hematoxylin-eosin and phosphotungstic acid hematoxylin stains. Morphologic features assessed included cellularity, degree of pleomorphism, mitotic activity, presence of necrosis, calcification, microcystic change, pattern of vascularity and presence of vascular hyperplasia.

For electronmicroscopy (EM), glutaraldehyde-fixed, postosmicated, epon-embedded tissue was sectioned and examined using a Philips 400 electronmicroscope. EM studies were performed in nine of the 14 cases.

Formalin-fixed paraffin-embedded tissue from all cases was studied immunohistochemically with antisera to GFAP, S-100, vimentin and neuron-specific enolase (NSE), using the peroxidaseantiperoxidase method as previously published." The dilutions of various antisera and controls were as follows: GFAP(DAKO, polyclonal, 1:300), vimentin (Laboratory Systems, monoclonal, 1:10), S-100(DAKO, polyclonal, 1:200), NSE (DAKO, polyclonal, 1:300). The specificity of the vimentin antibodies was tested by immunoblotting of electrophoretically separated polypeptides of cultured human fibroblasts and of cultured human rhabdomyosarcoma cells, where the monoclonal vimentin antibodies recognize a 58,000-dalton polypeptide.

To compare the immunohistochemical staining patterns of oligodendrogliomas and immature oligodendroglia, cerebral and cerebellar cortex and white matter of normal brains from eight children under 6 months of age were studied. Formalin-fixed paraffin-embedded tissue was sectioned and stained with hematoxylin-eosin. Immunohistochemical studies with antisera to GFAP and vimentin used the same methodology as was employed in the study of oligodendrogliomas.

\section{Results \\ Light microscopic findings in tumors}

All tumors possessed features typical of oligodendrogliomas with uniform round cells and a delicate vascular stroma inter- secting the tumor cells (Figure 1). Tumors were graded on the basis of cellularity, mitotic activity, cellular pleomorphism and necrosis. The four identified as high-grade had moderate or marked pleomorphism; the ten low-grade tumors had mild or no pleomorphism. Focal endothelial hyperplasia was present in three tumors. Five tumors showed variable degrees of calcification. Microcystic change was prominent in one tumor. In one case (no. 9), numerous cells with eosinophilic cytoplasmic granules were found randomly scattered throughout the tumor; these granules were periodic acid Schiff-(PAS-) positive and diastase-resistant.

\section{Electronmicroscopic findings in tumors}

EM revealed polygonal cells with straight or interdigitating cell membranes (Figure 2). Light and dark cell types were present, the majority being the light cells, which had round-tooval nuclei with dense heterochromatin distributed peripherally. The cytoplasm of these cells contained mitochondria with some giant forms, few free ribosomes, short stacks of rough endoplasmic reticulum, microtubules, sparse Golgi complexes and occasional lysosomes. The dark cells constituted less than $10 \%$ of the total cell population and were scattered randomly between

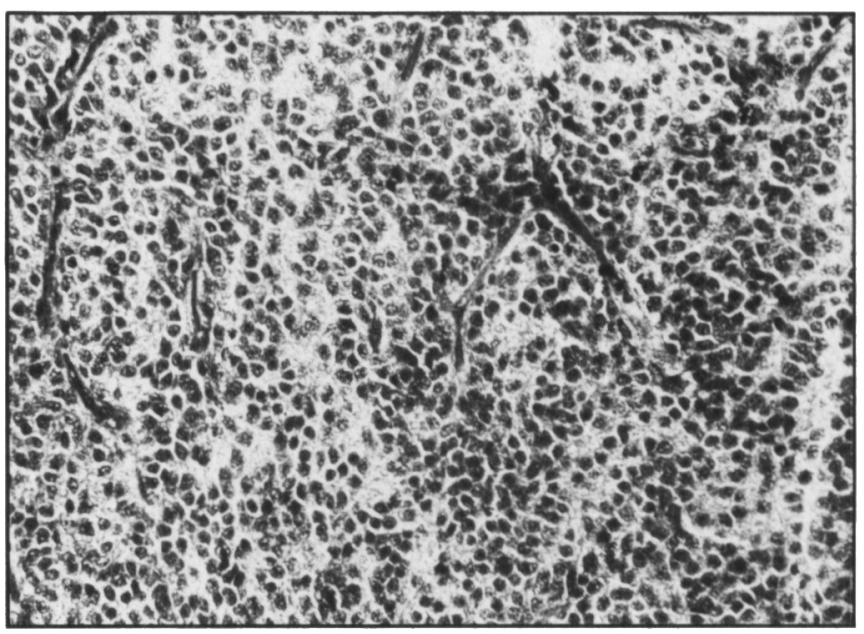

Figure I - Photomicrograph of a typical oligodendroglioma with a delicate vascular stroma intersecting nests of tumor cells (case 4). $H \& E \times 200$

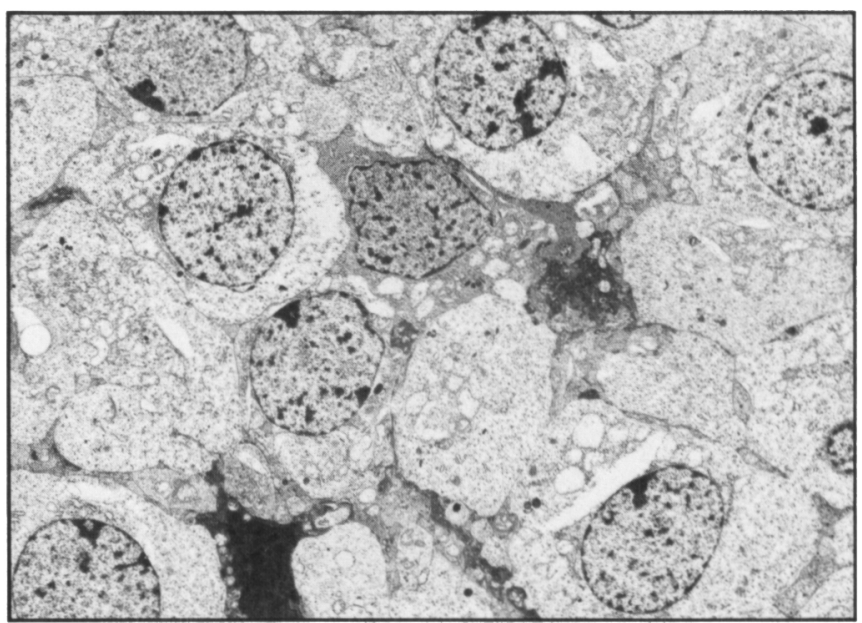

Figure 2 - Electronmicrograph showing polygonal cells with straight borders and a paucity of cell processes. Light and dark cells are evidem (case 4) $\times 3,960$ 


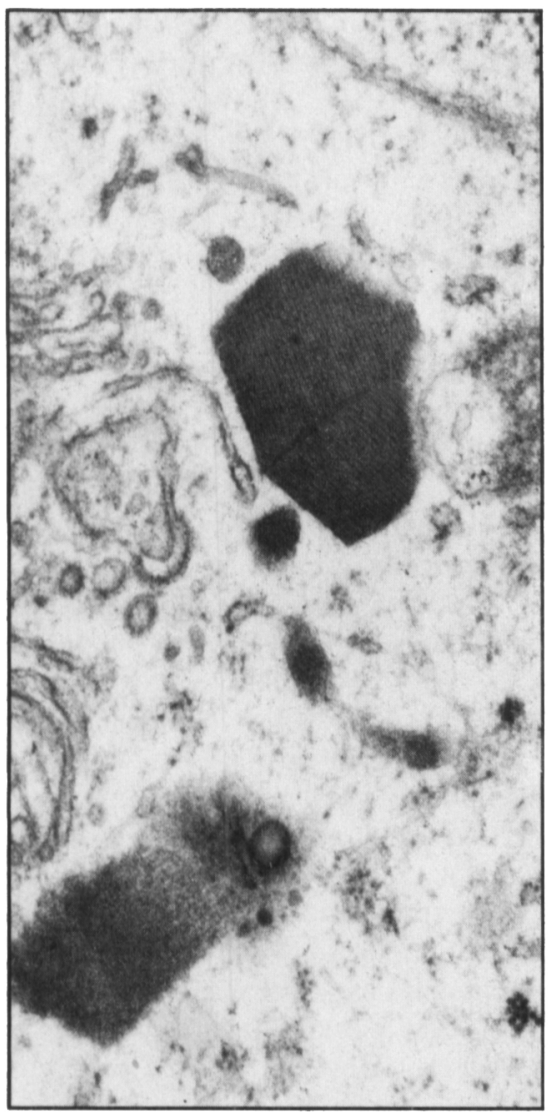

Figure $3-$ (A) Electronmicrograph of a tumor cell in case 9 showing polygonal crystalline structures in cytoplasm $\times 40,590$

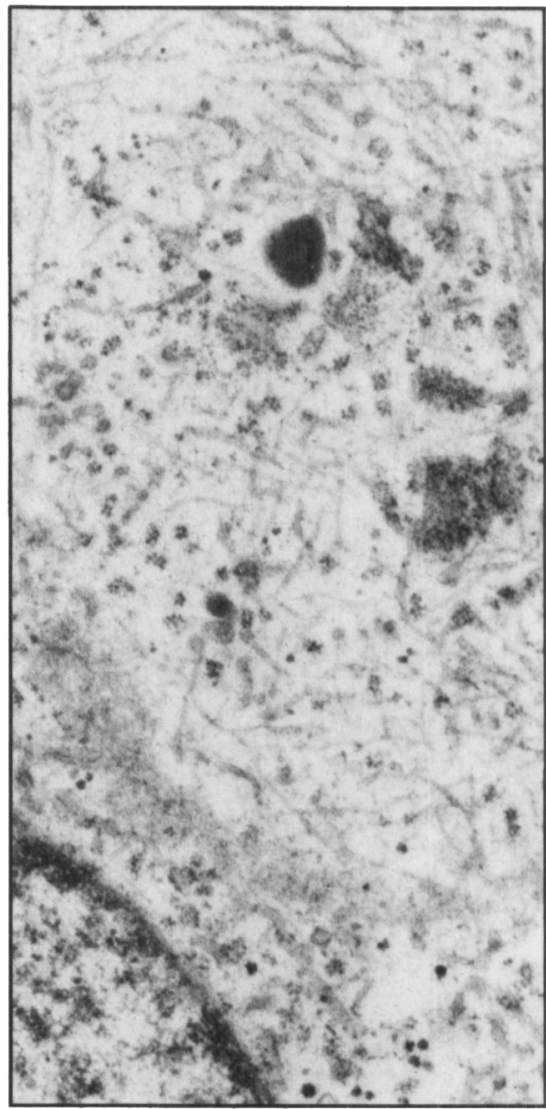

Figure $3-(B)$ Electronmicrograph of a tumor cell in case 9 showing microtubules in cyto. plasm $\times 2 I, 400$.

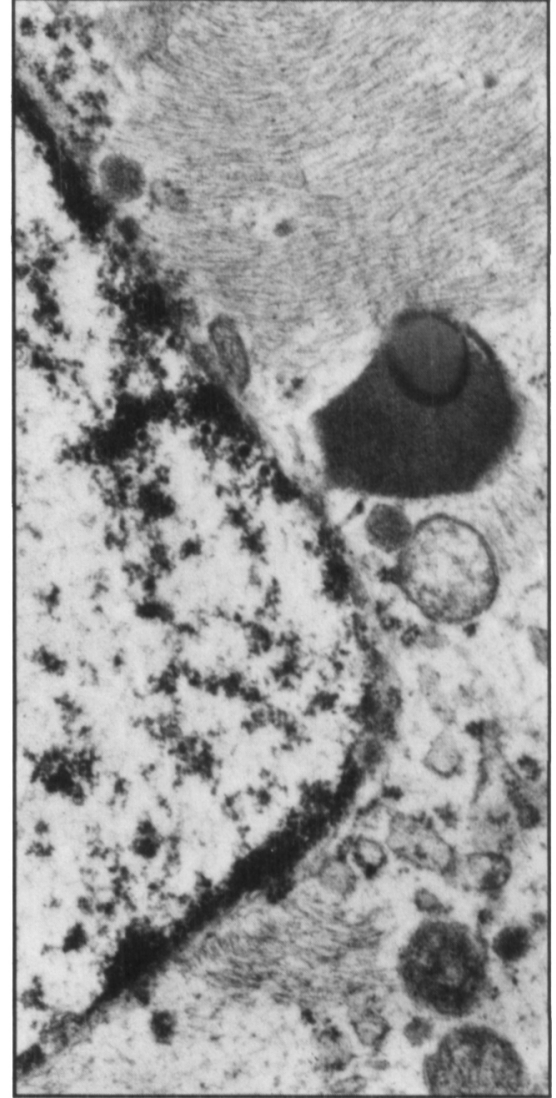

Figure $3-(C)$ Electronmicrograph of a tumor cell in case 9 showing intermediate filaments in cytoplasm $x 40,590$

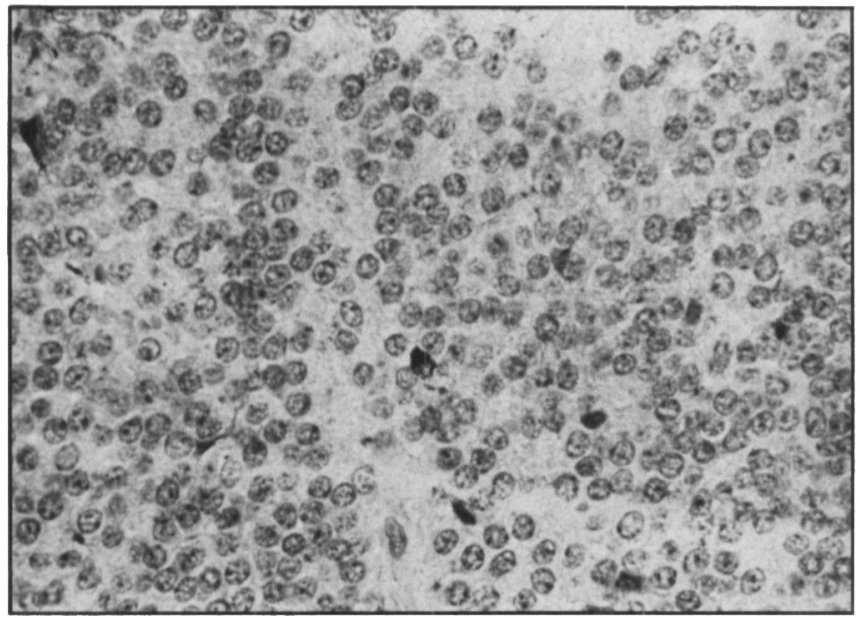

Figure 4-Tumor showing GFAP positivity in the cytoplasm of occasional tumor cells (case 4) $\times 320$.

the light cells. Their cytoplasm contained a few mitochondria, ribosomes, sparse endoplasmic reticulum and Golgi complexes. In both cell types, microtubules were present but intermediate filaments were not found.

In the tumor with cytoplasmic granules, polygonal crystalline structures with a rectangular or hexalinear configuration were identified (Figure 3). These showed linear densities spaced with a periodicity of $150 \AA$ with their axes intersecting at approximately 120 degrees. In the cytoplasm of these cells, both micro-

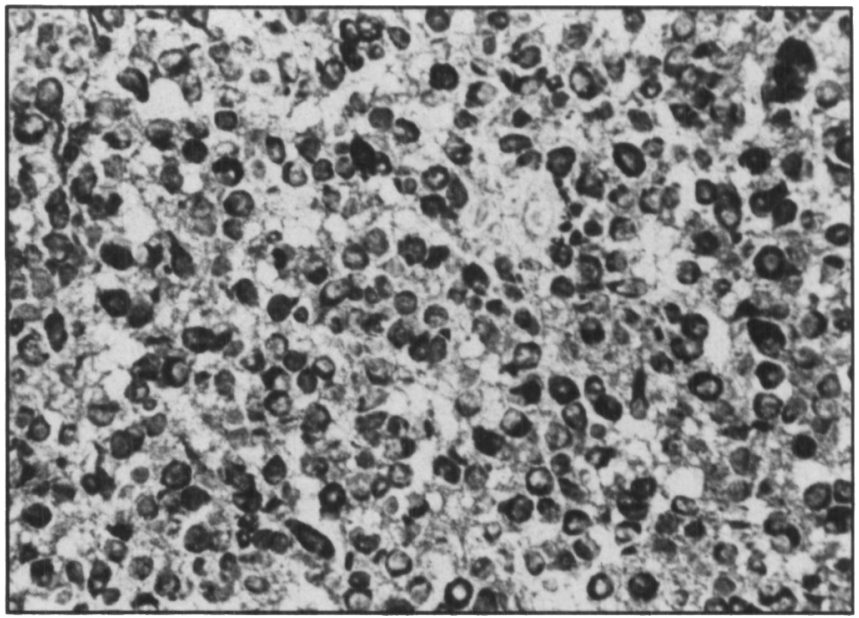

Figure 5 - Oligodendroglioma showing GFAP positivity in numerous Iumor cells (case 9) $\times 320$

tubules and intermediate filaments were found and a few autophagic vacuoles were identified.

\section{Immunohistochemical findings}

GFAP positivity was observed in nine patients in cells with features typical of oligodendroglia. This was localized to the cytoplasm in a variable number of cells; cells were rare to occasional in eight cases (Figure 4) and numerous in case 9 (Figure 5). The distribution of GFAP-positive cells was random. 
Positivity did not correlate with the degree of anaplasia; three high-grade tumors were GFAP-positive while the fourth was negative. The coarse staining of reactive astrocytes in scattered areas was morphologically distinct from the staining of the tumor cells.

Although the pattern was variable, all tumors stained positively with antisera to $S-100$, the antigen being localized to the nucleus, cytoplasm or both.

None of the tumors stained for vimentin or NSE.

\section{Immature oligodendroglia}

All immature oligodendroglia (myelination glia) in the developing white matter of the cerebrum and cerebellum showed positive cytoplasmic staining with antisera to GFAP and negative staining for vimentin.

\section{Discussion}

All tumors in this study showed features of pure oligodendrogliomas with no evidence of a mixed astrocytic component. Ultrastructurally, a two-cell population of light and dark cells was found, as observed by others. ${ }^{12.13}$ Both cell types showed a paucity of cell processes. The cytoplasmic organelles included mitochondria, sparse endoplasmic reticulum, Golgi complexes and free ribosomes. Microtubules were also present. There was some variation in the mitochondrial morphology with occasional giant forms. In case 9 , whose tumor had intracytoplasmic PAS-positive granules, crystalline inclusions, which have been described in the literature, ${ }^{12-15}$ were present. They are thought to be related to lysosomes, Golgi apparatus or mitochondria. In the case mentioned by Tani et al ${ }^{15}$ intermediate filaments were not present in the cytoplasm, but our case had both intermediate filaments and microtubules in occasional tumor cells. CervósNavarro et al ${ }^{13}$ reported seven tumors with intermediate filaments in the cytoplasm of cells with features typical of oligodendroglia.

All the tumors in our patients stained positively for antisera to $S-100$; however, positivity was present in only some tumor cells, sometimes in the nucleus, at other times in the cytoplasm or more commonly in both. This pattern of S-100 staining has been previously observed. ${ }^{16}$ The finding of NSE in tumor cells not related to the nervous system, such as carcinomas of the breast and ovary or lymphomas, suggests that its specificity as an indicator of neuronal origin or differentiation cannot be assumed. ${ }^{17}$ However, none of the oligodendrogliomas in our series stained for NSE.

GFAP positivity was present in nine tumors, in cells with features typical of oligodendroglia. In eight cases, only rare-tooccasional cells exhibited GFAP positivity, suggesting that such cells may be missed because of factors of sampling. In the tumor with cytoplasmic granules and crystalline inclusions (case 9), numerous cells expressed GFAP. This was the only tumor in which intermediate filaments were seen on EM. While sampling may be a factor, GFAP positivity does not always correlate with intermediate filament formation.?

GFAP-positive cells in oligodendrogliomas have been variably interpreted in earlier studies. ${ }^{6-10}$ Some authors have considered such cells to be astrocytic. ${ }^{7,8}$ Meneses et al ${ }^{8}$ proposed that GFAP positivity represented an astrocytic differentiation by the neoplastic oligodendroglia. Van der Meulen et al, ${ }^{6}$ who found GFAP positivity in malignant oligodendrogliomas, proposed that a degree of anaplasia or dedifferentiation may be required for GFAP expression. Correlation with malignancy could not be corroborated by us or in the study of Herpers and Budka.?

Some authors ${ }^{6.9}$ have proposed that GFAP-positive cells in oligodendrogliomas may represent transitions from oligodendroglia to astrocytes; such tumors have been termed "transitional" oligodendrogliomas. ${ }^{9}$ Evidence for the existence of such transitional elements is based on the production of cytoplasmic intermediate filaments by oligodendroglia under various experimental conditions. For example, Hirano and Zimmerman ${ }^{18}$ showed intermediate filament formation in the inner and outer loops of myelin sheaths in the rat forebrain after vinblastine implantation. Also, Bunge et al ${ }^{19}$ described filaments in trapped cytoplasmic areas with myelin sheaths in spinal cords of animals experiencing remyelination after experimental cord injury.

A further explanation of GFAP positivity in oligodendrogliomas is suggested by the transient presence of GFAP in immature oligodendroglia during the stage of myelination glia. ${ }^{11,20,21}$ In correlative immunocytochemical and electronmicroscopic studies, Choi and $\mathrm{Kim}^{21}$ showed GFAP positivity in immature oligodendroglia in the human fetal spinal cord between 12 and 18 weeks gestation, which was no longer evident by 17 to 18 weeks. Raff et $\mathrm{al}^{22}$ suggested the existence of a bipotential glial precursor cell based on the experiments on rat optic nerves. They demonstrated that a cell in the 7-day-old rat optic nerve had the ability to differentiate into an astrocyte, if cultured in the presence of fetal calf serum, or an oligodendrocyte, if cultured without the calf serum. However, with a common precursor, GFAP-positive oligodendroglia should predominate in mixed glial tumors, rather than in pure oligodendrogliomas as found by Herpers and Budka. ${ }^{9}$

In our patients, the finding of GFAP positivity with negative vimentin further supports the oligodendroglial nature of the cells in question. Vimentin exists in developing, reactive and neoplastic astrocytes. ${ }^{23-28}$ It is expressed in mouse astroctyes in glial precursors well before the onset of GFAP expression, ${ }^{25}$ and is the major cytoskeletal component of immature glia in the newborn rat brain. ${ }^{24}$ Vimentin also persists in mature astrocytes. ${ }^{23}$ In neoplastic astrocytes, both vimentin and GFAP are present but vimentin expression may predominate. ${ }^{27}$ The GFAP-positive cells in all our tumors did not express vimentin, suggesting that they are not astrocytic in nature. Similarly, the immature oligodendroglia in the eight normal brains were also vimentinnegative and GFAP-positive.

In conclusion, cells immunoreactive for GFAP may be encountered in otherwise classical oligodendrogliomas. Such cells need not represent an added astrocytic element or astrocytic line of differentiation. More likely they reflect the transient expression of GFAP in immature oligodendroglia during an early phase of development.

\section{ACKNOWLEDGEMENT}

This paper was prepared with the assistance of the Medical Publications Department, The Hospital for Sick Children.

\section{REFERENCES}

1. Eng LF, Vanderhaeghen JJ, Bignami A, et al. An acidic protein isolated from fibrous astrocytes. Brain Res 1971; 28: 351-354.

2. Bignami A, Eng LF, Dahl D, et al. Localization of the glial fibrillary acidic protein in astrocytes by immunofluorescence. Brain Res 1972; 43: 429-435. 
3. Dahl D. Glial fibrillary acidic protein from bovine and rat brain. Degradation in tissues and homogenates. Biochim Biophys Acta 1976; 420: 142-154.

4. Deck JHN, Eng LF, Bigbee J, Woodcock SM. The role of glial fibrillary acidic protein in the diagnosis of central nervous system tumors. Acta Neuropathol (Berl) 1978; 42: 183-190.

5. Velasco ME, Dahl D, Roessmann U, Gambetti P. Immunohistochemical localization of glial fibrillary acidic protein in human glial neoplasms. Cancer 1980; 45: 484-494.

6. Van der Meulen JDM, Houthoff HJ, Ebels EJ. Glial fibrillary acidic protein in human gliomas. Neuropathol Appl Neurobiol 1978; 4: 177-190.

7. de Armond SJ, Eng LF, Rubinstein LJ. The application of glial fibrillary acidic (GFA) protein immunohistochemistry in neurooncology. A progress report. Pathol Res Pract 1980; 168: 374-394.

8. Meneses ACO, Kepes JJ, Sternberger NH. Astrocytic differentiation of neoplastic oligodendrocytes. J Neuropathol Exp Neurol 1982; 41: 368 (abstract).

9. Herpers MJHM, Budka H. Glial fibrillary acidic protein (GFAP) in oligodendroglial tumors: gliofibrillary oligodendroglioma and transitional oligoastrocytoma as subtypes of oligodendroglioma. Acta Neuropathol (Berl) 1984; 64: 265-272.

10. Liao SY, Choi BH. Immature and neoplastic oligodendroglia express immunoreactive glial fibrillary acidic protein (abstract) Fed Proc 1984; 43: 928 .

11. Takashima S, Becker LE. Developmental changes of glial fibrillary acidic protein in cerebral white matter. Arch Neurol 1983;40: 14-18.

12. Cervós-Navarro J, Pehlivan N. Ultrastructure of oligodendrogliomas Acta Neuropathol (Berl) 1981; [Supp] 7: 91-93.

13. Cervós-Navarro J, Ferszt R, Brackertz M. The ultrastructure of oligodendrogliomas. Neurosurg Rev 1981; 4: 17-31.

14. Raimondi AJ, Mullan S, Evans JP. Human brain tumors: an electronmicroscopic study. J Neurosurg 1962; 19: 731-753.

15. Tani E, Yamashita J, Takeuchi J, Handa H: Polygonal crystalline structures and crystalline aggregates of cylindrical particles in human glioma. Acta Neuropathol (Berl) 1969; 13: 324-337.

16. Nakajima T, Watanabe S, Sato Y, Kameya T, Hirota T, Shimosato $Y$. An immunoperoxidase study of S-100 protein distribution in normal and neoplastic tissues. Am J Surg Pathol 1982;6: 715-727.
17. Wick MR, Scheithauer BW, Kovacs K. Neuron-specific enolase in neuroendocrine tumors of the thymus, bronchus, and skin. Am J Clin Pathol 1983; 79: 703-707.

18. Hirano A, Zimmerman. HM. Glial filaments in the myelin sheath after vinblastine implantation. J Neuropathol Exp Neurol 1971: 30: 63-67.

19. Bunge $M B, B$ unge RP, Ris $\mathrm{H}$. Ultrastructural study of remyelination in an experimental lesion in adult cat spinal cord. J Biophys Biochem Cytol 1961; 10: 67-94

20. Choi BH, Kim RC. Expression of glial fibrillary acidic protein in immature oligodendroglia. Science 1984; 223: 407-409.

21. Choi BH, Kim RC. Expression of glial fibrillary acidic protein by immature oligodendroglia and its implications. J Neuroimmunol 1985; 8: 215-235.

22. Raff MC, Miller RH, Noble M. A glial progenitor cell that develops in vitro into an astrocyte or an oligodendrocyte depending on culture medium. Nature 1983: 303: 390-396.

23. Dahl D, Bignami A, Weber K, Osborn M. Filament proteins in rat optic nerves undergoing Wallerian degeneration: localization of vimentin, the fibroblastic 100-A filament protein, in normal and reactive astrocytes. Exp Neurol 1981; 73: 496-506.

24. Dahl D, Rueger DC, Bignami A, Weber K, Osborn M. Vimentin. the 57000 molecular weight protein of fibroblast filaments. is the major cytoskeletal component in immature glia. Eur J Cell Biol 1981; 24: 191-196.

25. Schnitzer J, Franke WW, Schachner M. Immunocytochemical demonstration of vimentin in astroctyes and ependymal cells of developing and adult mouse nervous system. J Cell Biol 1981: 90: 435-447.

26. Borit A, Yung A. Glial fibrillary acidic protein (GFAP) and vimentin in brain tumors. (abstract) J Neuropathol Exp Neurol 1983; 42: 308 .

27. Roessmann V, Velasco ME, Gambetti P, Autilio-Gambetti L. Vimentin intermediate filaments are increased in human neoplastic astrocytes. (abstract)] Neuropathol Exp Neurol 1983;42:309.

28. Fedoroff S, White R, Neal J, Subrahmanyan L. Kalnins VI. Astrocyte cell lineage II. Mouse fibrous astrocytes and reactive astrocytes in cultures have vimentin and GFP containing intermediate filaments. Brain Res 1983; 283: 303-315. 